\title{
A Genomic and Proteomic Approach to Identify and Quantify the Expressed Bacillus thuringiensis Proteins in the Supernatant and Parasporal Crystal
}

\author{
Joaquín Gomis-Cebolla $^{1}$ (), Ana Paula Scaramal Ricietto ${ }^{1,2}$ and Juan Ferré ${ }^{1, * \text { (1) }}$ \\ 1 ERI de Biotecnología y Biomedicina (BIOTECMED), Department of Genetics, Universitat de València, \\ 46100 Burjassot, Spain; Joaquin.Gomis@uv.es (J.G.-C.); ricietto@gmail.com (A.P.S.R.) \\ 2 Departamento de Biologia Geral, Universidade Estadual de Londrina, Londrina 86057-970, Paraná, Brazil \\ * Correspondence: Juan.Ferre@uv.es; Tel.: +34-96-354-4506
}

Received: 13 April 2018; Accepted: 7 May 2018; Published: 10 May 2018

\begin{abstract}
The combined analysis of genomic and proteomic data allowed us to determine which cry and vip genes are present in a Bacillus thuringiensis (Bt) isolate and which ones are being expressed. Nine $B t$ isolates were selected from Spanish collections of $B t$ based on their vip1 and vip2 gene content. As a first step, nine isolates were analyzed by PCR to select those $B t$ isolates that contained genes with the lowest similarity to already described vip1 and vip2 genes (isolates E-SE10.2 and O-V84.2). Two selected isolates were subjected to a combined genomic and proteomic analysis. The results showed that the $B t$ isolate E-SE10.2 codifies for two new vegetative proteins, Vip2Ac-like_1 and Sip1Aa-like_1, that do not show expression differences at $24 \mathrm{~h}$ vs. $48 \mathrm{~h}$ and are expressed in a low amount. The Bt isolate O-V84.2 codifies for three new vegetative proteins, Vip4Aa-like_1, Vip4Aa-like_2, and Vip2Ac-like_2, that are marginally expressed. The Vip4Aa-like_1 protein was two-fold more abundant at 24 h vs. 48 h, while the Vip4Aa-like_2 was detected only at $24 \mathrm{~h}$. For Vip2Ac-like_2, no differences in expression were found at $24 \mathrm{~h}$ vs. $48 \mathrm{~h}$. Moreover, the parasporal crystal of the E-SE10.2 isolate contains a single type of crystal protein, Cry23Aa-like, while the parasporal crystal from O-V84.2 contains three kinds of crystal proteins: 7.0-9.8\% weight of Cry45Aa-like proteins, 35-37\% weight of Cry32-like proteins and 2.8-4.3\% weight of Cry73-like protein.
\end{abstract}

Keywords: insect pest control; crop protection; vip proteins; cry proteins

\section{Key Contribution:}

- Genomic and proteomic analysis can identify insecticidal proteins genes and quantify their expressed products.

- The Bt isolates E-SE10.2 and O-V84.2 produce five new Vip-like and Sip-like proteins and eight new Cry-like proteins

\section{Introduction}

Bacillus thuringiensis $(B t)$ is an entomopathogenic bacterium that produces several types of insecticidal proteins, such as Cry, Cyt, Vip, Sip, Mtx-like, and Bin-like proteins, along with other virulence factors contributing to its pathogenicity [1,2]. The Vip proteins are a family of proteins that are secreted during the vegetative growth phase and that have been classified into four groups according to their sequence homology: Vip1, Vip2, Vip3, and Vip4 [2]. Because of repeated applications of $B t$ sprays and the widespread adoption of $B t$-crops (transgenic crops protected from insects by the expression of $c r y$ and/or vip3 genes), some insect populations have developed resistance to $B t$ 
toxins [3-6]. Therefore, in this arms race against insects, it is necessary to explore the potential of new insecticidal proteins for pest control. A series of approaches have been used for isolating novel insecticidal protein genes from $B t$, such as $\mathrm{PCR}$, which has further evolved into specific applications to mining new insecticidal genes, such as PCR hybridization, PCR-RFLP, E-PCR and PCRSSCP [7-11]. In addition, the construction of $B t$ DNA libraries, followed by screening by Western Blotting or a hybridization-based method, has also been used to detect novel insecticidal protein genes [12-14]. The PCR approaches being used to detect vip genes are based on the presence of conserved blocks in the DNA sequence of these genes $[11,15]$ and most of the studies have focused on genes from the vip3 family. Therefore, the PCR approach is limited to finding vip genes with enough homology to the primers used. An additional problem with the PCR approach is that it does not provide the full length of the new vip genes. On the other hand, the library-based methods are time-consuming and laborious. The next generation sequencing (NGS) allows rapid sequencing of entire genomes at a low cost-effective ratio $[16,17]$. The number of $B t$ whole genomes that have been sequenced has increased quickly in the past decade. To date, $459 \mathrm{Bt}$ strains have been sequenced, with a mean genome size ranging from $5.3 \mathrm{MB}$ to $6.7 \mathrm{MB}$ and a mean guanine-cytosine content (GC content) between $34 \%$ and 35\% (https: / / www.ncbi.nlm.nih.gov/genome/?term=Bacillus+thuringiensis). The combination of the low cost NGS with the development of many freeware tools has enabled the rapid detection of insecticidal protein genes at the genome level. On the other hand, the development of the mass spectrometry (MS)-based proteomics has enabled the detection of proteins from complex mixtures from different stages of a microorganism [18]. The combination of the genomic and proteomic approaches is a very successful approach for validation and correction of predicted genomic coding information in a wide variety of organisms [18-22].

In this study, the identity of vip genes has been determined in nine $B t$ isolates which were candidates to harboring new vip1 and vip2 genes (Vip1 and Vip2 constitute a binary toxin and their genes are normally located in an operon). Two of these isolates, which were found to carry vip-type genes with a similarity lower than $45 \%$ to already reported genes, were subjected to whole genome sequencing and to different kinds of proteomic analysis to determine and estimate the relative abundance of the expressed insecticidal protein genes.

\section{Results}

\subsection{Identification of Vip1-, Vip2-, and Vip4-Type Genes}

To identify the specific genes within the vip1 and vip2 gene families, a strategy based on PCR-Sanger Sequencing was used. A first PCR with "screening primers" was performed to confirm the presence of vip genes. The results showed that the nine isolates were positive for the presence of a vip1-type gene, and that seven were positive for the presence of a vip2-type gene (Table 1). Those samples that gave positive for a determined gene type were subjected to a second PCR with "typing primers" to narrow down the identity of the gene. The results allowed us to classify the isolates into two types of isolates containing a vip1-vip2 gene pair: those with a gene pair with high similarity ( $>95 \%)$ to vip2Bb (KR065728)-vip1Bb (KR065727) (V-J20.2 and V-LE1.1), and those with a gene pair with high similarity to vip2Ac (KR065726)-vip1Ca (KR065725) (V-V54.26, V-V54.31, E-TE7.43, E-TE16.5 and E-TE18.40). In addition to these two categories, two isolates were identified to contain just a single vip gene with low similarity to all reported ones; one had the highest similarity to vip1Bb (E-SE10.2) and the other had the highest similarity to vip1Da (O-V84.2), which was later shown to belong to the vip4Aa family (Table 1). 
Table 1. Identification of vip1, vip2 and vip4 genes in selected isolates of Bacillus thuringiensis.

\begin{tabular}{|c|c|c|c|c|c|c|}
\hline \multirow{2}{*}{ Name of Isolate } & \multicolumn{3}{|c|}{ Identified with vip1 Primers } & \multicolumn{3}{|c|}{ Identified with vip2 Primers } \\
\hline & Similarity $(\%) \ddagger$ & Coverage $(\%) *$ & Closest Homolog & Similarity $(\%) \ddagger$ & Coverage $(\%) *$ & Closest Homolog \\
\hline V-J20.2 & 100 & 44 & vip1Bb1 & 97 & 70 & vip2Bb1 \\
\hline V-LE1.1 & 100 & 40 & vip1Bb1 & 99 & 72 & vip2Bb1 \\
\hline V-V54.26 & 99 & 49 & vip1Ca1 & 99 & 71 & vip $2 A c 1$ \\
\hline V-V54.31 & 100 & 49 & vip1Ca1 & 98 & 73 & $\operatorname{vip} 2 A c 1$ \\
\hline E-SE10.2 & 62 & 30 & vip1Bb3 & \multicolumn{3}{|c|}{ No DNA amplification } \\
\hline E-TE7.43 & 100 & 49 & vip1Ca1 & 99 & 64 & $\operatorname{vip} 2 A c 1$ \\
\hline E-TE16.5 & 98 & 43 & vip1Ca1 & 98 & 73 & $\operatorname{vip} 2 A c 1$ \\
\hline E-TE18.40 & 100 & 30 & vip1Ca1 & 100 & 45 & $\operatorname{vip} 2 A c 1$ \\
\hline O-V84.2 & 40 & 40 & vip4Aa1 & \multicolumn{3}{|c|}{ No DNA amplification } \\
\hline
\end{tabular}

* The coverage values represent the mean of two replicates of the typing or screening PCR products to the full sequence length of the respective vip1, vip2 and vip4 genes deposited in GenBank. $¥$ The similarity values provided by BlastX (NCBI) represent the mean value of the in silico translation of two replicates of the PCR products.

\subsection{Genome Sequencing of the Bt Isolates E-SE10.2 and O-V84.2, Contig Assembly and Gene Annotation}

Whole genome sequencing of the $B t$ isolates E-SE10.2 and O-V84.2 resulted in 10,401,436 high quality reads for the $B t$ isolate E-SE10.2 and 9,210,116 high quality reads for the $B t$ isolate O-V84.2, with an average length of $150 \mathrm{bp}$ for both $B t$ isolates. For the E-SE10.2 isolate, the $97.4 \%$ of the reads were assembled in 222 scaffolds while for the O-V84.2 isolate the $98.2 \%$ of the reads were assembled in 249 scaffolds. For the E-SE10.2 isolate, the results of the assembled paired reads were as follows: genome size of $6.1 \mathrm{Mb}$, N50 was $71 \mathrm{~kb}$, the GC content 36\%, and the longest scaffold length was $258 \mathrm{~kb}$. For the O-V84.2 isolate, the genome size was $6.3 \mathrm{Mb}$, N50 was $123 \mathrm{~kb}$, the GC content 36\%, and the longest scaffold length was $336 \mathrm{~kb}$. Coding sequence prediction of the assembled reads showed that the 222 scaffolds of the E-SE10.2 isolate defined 6156 coding sequences (CDS) and that the 249 scaffolds of the O-V84.2 isolate defined 6457 CDS. For both isolates, the CDS represented the $79 \%$ of the length of the bacterial genome, and contained $71.5 \%$ of annotated genes, $28.5 \%$ of hypothetical genes, and 60-68 tRNAs (Table 2). In addition, for both isolates, $60 \%$ of the CDS could be associated to a subsystem category, being more abundant the ones associated with amino acids and derivatives, carbohydrates, protein metabolism, and cofactors, prostetic groups and pigments, in decreasing order (Figure S1).

Table 2. Summary of the automated genome annotation of the Bt isolates E-SE10.2 and O-V84.2 by the Rast server.

\begin{tabular}{ccccc}
\hline \multirow{2}{*}{ Features } & \multicolumn{2}{c}{ E-SE10.2 } & \multicolumn{2}{c}{ O-V84.2 } \\
\cline { 2 - 5 } & Gene Content & Length $\mathbf{( M b )}$ & Gene Content & Length $\mathbf{( M b )}$ \\
\hline Genome Content * & 6216 & 6.1 & 6525 & 6.3 \\
Coding sequences $\ddagger$ & $6156(99 \%)$ & 4.8 & $6457(98.9 \%)$ & 5 \\
Annotated genes & $4398(70 \%)$ & 4.05 & $4615(71.4 \%)$ & 4.21 \\
Hypothetical genes & $1758(28.2 \%)$ & 0.75 & $1842(28.2 \%)$ & 0.79 \\
Predicted insecticidal genes $§$ & 6 & 0.002 & 18 & 0.4 \\
tRNAs & 60 & 0.004 & 68 & 0.005 \\
\hline
\end{tabular}

* The gene content values refer the total of predicted sequences (Coding sequences and tRNAs) predicted by the Rast server. $\ddagger$ The coding sequences values refer to the total predicted sequences (protein encoding genes and rRNA). The annotated genes refer to the predicted sequences that were included in subsystem category, while the hypothetical genes refer to the predicted sequences that were not included in any subsystem category. The percentage of coding sequences was calculated by dividing the values of the coding sequences, annotated genes and hypothetical genes, by the value of genome content. \$ The predicted insecticidal genes refer to the coding sequences that report similarity to the homemade $B t$ database at amino acid level (BlastX).

Regarding the insecticidal protein genes present in the Bt isolates E-SE10.2 and O-V84.2, the results indicated a total of 24 coding sequences (6 in E-SE10.2 and 18 in O-V84.2) (Table 3). For the Bt isolate E-SE10.2, four out of the six sequences showed homology to a vip gene, one to a sip gene and one to a cry gene (Table 3). In the case of the $B t$ isolate O-V84.2, 10 out of the 18 sequences showed homology to a vip gene, one to a sip gene and seven to a cry gene (Table 3). 
Table 3. Insecticidal genes of the E-SE10.2 and O-V84.2 isolates predicted by Glimmer v2 software and filtered against a customized $B t$ protein database and then with the non-redundant database (NCBI).

\begin{tabular}{|c|c|c|c|c|}
\hline Sample & Gene Identity ${ }^{\ddagger}$ & Closest Homolog * & Similarity (\%) & Coverage (\%) \\
\hline \multirow{6}{*}{ E-SE10.2 } & vip1Ad-like_1 & AGC08395.1 & 55 & 24 \\
\hline & vip1Bb-like_1 & AAR40282.1 & 61 & 99 \\
\hline & vip2Aa-like & 1QS1_A & 41 & 23 \\
\hline & vip2Ac-like_1 & AAO86513.1 & 30 & 30 \\
\hline & sip1Aa-like_1 & ABC71340.1 & 75 & 98 \\
\hline & cry23Aa-like & AAF76375.1 & 75 & 98 \\
\hline \multirow{18}{*}{ O-V84.2 } & vip1Ad-like_2 & AGC08395.1 & 26 & 34 \\
\hline & vip1Ba-like & AAR40886.1 & 28 & 30 \\
\hline & vip1Da-like & CAI40767.1 & 37 & 12 \\
\hline & vip2Ac-like_2 & AAO86513.1 & 33 & 47 \\
\hline & vip2Ac-like_3 & AAO86513.1 & 37 & 41 \\
\hline & vip2Bb-like & AKI69695.1 & 30 & 43 \\
\hline & vip4Aa1-like_1 & AEB52299.1 & 40 & 80 \\
\hline & vip4Aa1-like_2 & AEB52299.1 & 40 & 83 \\
\hline & vip4Aa-like_3 & AEB52299.1 & 49 & 94 \\
\hline & vip4Aa-like_4 & AEB52299.1 & 52 & 97 \\
\hline & sip1Aa-like_3 & ABC71340.1 & 32 & 33 \\
\hline & cry 45 Aa-like_1 & BAD22577.1 & 61 & 100 \\
\hline & cry 45 Aa-like_2 & BAD22577.1 & 69 & 99 \\
\hline & cry 45 Aa-like_3 & BAD22577.1 & 68 & 85 \\
\hline & cry32Ea-like & ADK66923.1 & 47 & 98 \\
\hline & cry32Eb-like & AGU13828.1 & 51 & 41 \\
\hline & cry32Da-like & BAB78603.1 & 40 & 98 \\
\hline & cry73Aa-like & AEH76822.1 & 88 & 80 \\
\hline
\end{tabular}

$\ddagger$ The genes predicted by the gene prediction software were named based on the homologous gene in the database that showed more identity and coverage in the BlastX. * Access number of the gene that showed the highest identity in the protein database considered in the analysis.

\subsection{Global Analysis of the Proteins Identified by in Gel Digestion LC/MSMS Analysis of the Bt Isolates} E-SE10.2 and $O-V 84.2$

To determine the proteins that are being expressed in the Bt isolates E-SE10.2 and O-V84.2, an LC/MSMS analysis was done. By this method, we first screened the protein content in the concentrated supernatants and in the parasporal crystals at three growth phases, two during the log phase of growth (Phase T1 at $24 \mathrm{~h}$ and Phase T2 at $48 \mathrm{~h}$ ), and one in the stationary phase when the crystal is formed (Phase T3 at $72 \mathrm{~h}$ ). In the concentrated supernatant at Phase T1, 627 and 225 proteins were identified for E-SE10.2 and O-V84.2, respectively, while, at Phase T2, the number of proteins identified were 637 and 530, respectively. In the case of the proteins identified in the solubilized crystal (Phase T3), the numbers were 512 and 185, respectively. A total of 1791 and 940, respectively, were identified considering the three growth phases together and this represents about the $29.03 \%$ and $14.55 \%$ of the respective predicted proteins from the genomic data for the Bt isolates E-SE10.2 and $\mathrm{O}-\mathrm{V} 84.2$. The pairwise comparison of the identified proteins at the T1, T2 and T3 growth phases showed that the shared expressed proteins of the T1-T2, T2-T3, and T1-T3 phases were 406 and 160, 221 and 73, 219 and 33, respectively, for the Bt isolates E-SE10.2 and O-V84.2. The identified proteins of $B t$ isolates E-SE10.2 and O-V84.2 at the three growth phases were classified according to their gene ontology (GO) terms (Figure S2).

\subsection{Protein Identification of the Expressed Predicted Putative Insecticidal Protein Genes}

To determine if the predicted insecticidal protein genes are being expressed, the protein expression was assessed by proteomic analysis. We considered a positive identification only those proteins that were identified with both Protein Pilot v4.5 and Mascot algorithms in at least two of the replicates. Considering the two isolates together, we found a total of five secretable proteins (Vip-like and Sip-like) 
and eight crystal proteins (Cry-like and Mtx-like) (Table 4 and Tables S1-S3). For the E-SE10.2 isolate, only three out of the six putative insecticidal protein genes automatically annotated were found to be expressed (Table 3), and 10 out of 18, in the case of the O-V84.2 isolate (the seven Cry proteins, the Vip2Ac-like_2 protein, and the two Vip4-like proteins). Regarding the Vip2Ac-like_3 protein, it was detected just in one replicate with Mascot (Table 4 and Table S3) and the Sip1Aa-like_2 protein was detected in two replicates, but in one of them only with Mascot (Table 4, Tables S1 and S3) and, therefore, the Vip2Ac-like_3 and Sip1Aa-like_2 proteins were not considered a positive identification.

According to the similarity to the closest homolog, the Vip2Ac-like, Vip4Aa-like, Cry32Aa-like and Sip1Aa-like_2 proteins could be considered new Bt-like proteins (different to Cry, Vip or Sip because of a similarity lower than 45\%). Regarding the Cry45Aa-like, Cry73Aa-like, Cry23Aa-like and Sip1Aa-like-1 proteins, according to the similarity to the closest homolog (between $45 \%$ and $75 \%$ ), they could be considered new protein families of their respective reference proteins (e.g., with a different number) (Table 3). Regarding the subcellular localization of the putative insecticidal proteins, we performed an LC/MSMS analysis with the concentrated culture supernatants and with the solubilized crystal proteins (Table 4). In the supernatant of the culture broth, we could detect at $24 \mathrm{~h}$ and $48 \mathrm{~h}$ the Vip2Ac-like_1, Sip1Aa-like_1 and Cry23Aa-like proteins in the Bt isolate E-SE10.2. For the Bt isolate O-V84.2, we detected Vip4Aa-like_1, Vip4Aa-like_2 and Vip2Ac-like_2 proteins at $24 \mathrm{~h}$, whereas, at $48 \mathrm{~h}$, we detected Vip4Aa-like_1 and Vip2Ac-like_2 proteins (Table 4). In the fraction of solubilized crystal proteins, we detected the Cry23Aa-like protein in the Bt isolate E-SE10.2, while, for the Bt isolate O-V84.2, we detected the Cry45Aa-like_1, Cry45Aa-like_2, Cry45Aa-like_3, Cry32Ea-like, Cry32Eb-like, Cry32Da-like and Cry73Aa-like proteins. The putative insecticidal proteins identified in the supernatant and solubilized crystal agree with the prediction of the SignalIP server 4.0, except for the Cry23Aa-like protein which has been found in the supernatant and in the crystal even though it does not contain signal peptide to be exported out of the cell (Table 4). 
Table 4. Identification of expressed proteins from the identified putative insecticidal protein genes in the concentrated supernatant and in the solubilized proteins from the spore/crystal mixture of the Bt isolates E-SE10.2 and O-V84.2 by in gel digestion LC/MSMS analysis*.

\begin{tabular}{|c|c|c|c|c|c|c|c|c|c|c|c|c|}
\hline \multirow{3}{*}{ Sample } & \multirow{3}{*}{ Protein Identity } & \multirow{3}{*}{ Mass Protein (kDa) } & \multirow{3}{*}{ SignalIP Server 4.1} & \multicolumn{6}{|c|}{ Supernatant (LB) } & \multirow{2}{*}{\multicolumn{3}{|c|}{$\frac{\text { Spore/Crystal Mixture (CCY) }}{72 \mathrm{~h}}$}} \\
\hline & & & & \multicolumn{3}{|c|}{$24 \mathrm{~h}$} & \multicolumn{3}{|c|}{$48 \mathrm{~h}$} & & & \\
\hline & & & & Rep. 1 & Rep. 2 & Rep. 3 & Rep. 1 & Rep. 2 & Rep. 3 & Rep. 1 & Rep. 2 & Rep. 3 \\
\hline \multirow{3}{*}{ E-SE10.2 } & Vip2Ac-like_1 & 51.6 & Yes & $+/+$ & $+/+$ & $+/+$ & $+/+$ & $+/+$ & $+/+$ & $-1-$ & $-/-$ & $-/-$ \\
\hline & Sip1Aa-like_1 & 40.7 & Yes & $+/+$ & $+/+$ & $+/+$ & $+/+$ & $+/+$ & $+/+$ & $-1-$ & $-1-$ & $-1-$ \\
\hline & Cry23Aa-like & 29.3 & No & $+/+$ & $+/+$ & $+/+$ & $+/+$ & $+/+$ & $+/+$ & $+/+$ & $+/+$ & $+/+$ \\
\hline \multirow{12}{*}{ O-V84.2 } & Vip4Aa-like_1 & 97.5 & Yes & $+/+$ & $+/+$ & $+/+$ & $+/+$ & $+/+$ & $+/+$ & $-1-$ & $-1-$ & $-1-$ \\
\hline & Vip2Ac-like_2 & 80.79 & Yes & $+/+$ & $+/+$ & $+/+$ & $-1+$ & $+/+$ & $+/+$ & $-1-$ & $-1-$ & $-1-$ \\
\hline & Vip4Aa-like_2 & 87.5 & Yes & $+/+$ & $+/+$ & $-1+$ & $-1-$ & $-1-$ & $-1-$ & $-1-$ & $-1-$ & $-1-$ \\
\hline & Vip2Ac-like_3 & 23.2 & Yes & $-1-$ & $-/+$ & $-1-$ & $-1-$ & $-1-$ & $-1-$ & $-1-$ & $-1-$ & $-1-$ \\
\hline & Sip1Aa-like_2 & 38.7 & Yes & $-1-$ & $-1+$ & $+/+$ & $-1-$ & $-1-$ & $-1-$ & $-1-$ & $-1-$ & $-1-$ \\
\hline & Cry45Aa-like_1 & 30.6 & No & $-1-$ & $-1-$ & $-1-$ & $-1-$ & $-1-$ & $-1-$ & $+/+$ & $+/+$ & $+/+$ \\
\hline & Cry45Aa-like_2 & 29.3 & No & $-1-$ & $-1-$ & $-1-$ & $-1-$ & $-1-$ & $-1-$ & $+/+$ & $+/+$ & $+/+$ \\
\hline & Cry45Aa-like_3 & 25.6 & No & $-1-$ & $-1-$ & $-1-$ & $-1-$ & $-1-$ & $-1-$ & $+/+$ & $+/+$ & $+/+$ \\
\hline & Cry32Ea-like & 151.2 & No & $-1-$ & $-1-$ & $-1-$ & $-1-$ & $-1-$ & $-1-$ & $+/+$ & $+/+$ & $+/+$ \\
\hline & Cry32Da-like & 153.7 & No & $-1-$ & $-1-$ & $-1-$ & $-1-$ & $-1-$ & $-1-$ & $+/+$ & $+/+$ & $+/+$ \\
\hline & Cry32Eb-like & 76.8 & No & $-1-$ & $-1-$ & $-1-$ & $-1-$ & $-1-$ & $-1-$ & $+/+$ & $+/+$ & $+/+$ \\
\hline & Cry73Aa-like & 72.2 & No & $-1-$ & $-1-$ & $-1-$ & $-1-$ & $-1-$ & $-1-$ & $+/+$ & $+/+$ & $+/+$ \\
\hline
\end{tabular}

$*+/+$, the insecticidal protein genes were identified with Protein Pilot (Paragon algorithm) and Mascot; $+/-$, the insecticidal protein genes were identified with Protein Pilot (Paragon algorithm) but not with Mascot; $-/+$, the insecticidal protein genes were identified with Mascot but not Protein Pilot (Paragon algorithm); $-/-$, the insecticidal protein genes were not identified with either Protein Pilot (Paragon algorithm) or Mascot. 
2.5. Gene synteny, Conserved Domains and Phylogenetic Analysis of the Expressed Putative Insecticidal Protein Genes

In the E-SE10.2 isolate, the vip2Ac-like_1 gene was found in an operon together with a non-expressed vip1Bb-like gene, with the peculiarity that the vip1Bb-like gene was upstream of the vip2Ac-like_1 (Figure 1), contrary to the general relative location of vip1 and vip2 genes in operons. The cry32Aa-like gene was found in an operon with a predicted truncated cry37-like gene. In the O-V84.2 isolate, the genes for the Vip2Ac-like_2, Vip4Aa-like_1, and Vip4Aa-like_2 proteins were found in operons containing the pairs vip2Ac-like_2-vip4Aa-like_1 and vip2Ac-like_3-vip4Aa-like_2 (Figure 1). Regarding the cry genes of this isolate, they were found in different scaffolds with different transcription origins (Figure 1).
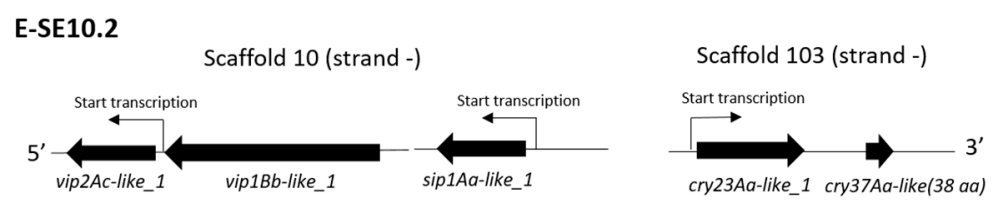

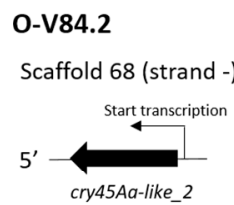

Scaffold 193 (strand -)

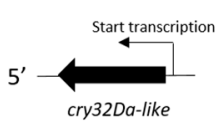

Scaffold 81 (strand -)

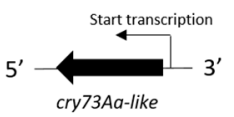

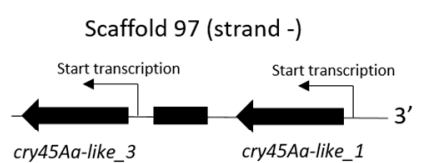

Scaffold 150 (strand-)
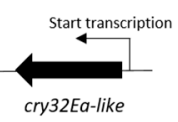

Scaffold 81 (strand-)

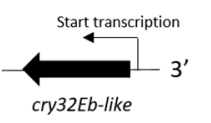

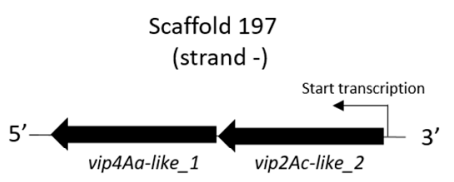

(strand +)

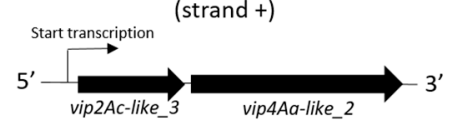

Scaffold 29 (strand -)

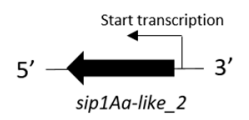

Figure 1. Gene synteny of the putative insecticidal protein genes of the E-SE10.2 and O-V84.2 isolates detected by LC/MSMS analysis. Strand + indicate that the respective genes are in the positive DNA strand. Strand-means that the respective genes are in the negative DNA strand.

The phylogenetic analysis of the Vip-like and Sip1-like proteins indicate that the Vip4-like, Vip2-like, and Sip1Aa-like_2 create a basal branch in their respective families (Figure 2). Regarding the Cry proteins, the Cry32E-like, Cry45Aa-like, Cry73Aa-like, and Cry23Aa-like proteins fall into their respective clusters, whereas the Cry32Da-like protein falls into the Cry66A cluster (Figure 3). The analysis of the sequences revealed that the vip4Aa-like_1 and vip4Aa-like_2 showed the predicted conserved domains of the PA14 superfamily and the clostridial binary toxin B/anthrax toxin PA, which are present in the Vip1 proteins. The vip2Ac-like_1, vip2Ac-like_2 and vip2Ac-like_3 genes showed the predicted conserved domain Vip2 superfamily, which is present in the Vip2 proteins. Moreover, vip2Ac-like_2 showed the predicted conserved domain anthrax toxin lethal factor (ATLF) and vip2Ac-like_3 showed one of the two Vip2 superfamily conserved domains present in the Vip2 proteins. The sip1Aa-like genes (sip1Aa-like_1 and sip1Aa-like_2) showed the predicted conserved domain of the MTX superfamily which is present in the Lysinibacillus sphearicus and Clostridium perfringens. Regarding the Cry-like proteins, the analysis of the sequences revealed that the cry23Aa-like gene and the cry45Aa-like genes (cry45Aa-like_1,cry45Aa-like_2, and cry45Aa-like_3 have a similarity of $75 \%$ to each other) showed the predicted conserved domain MTX. Among the cry32-like genes, cry32Ea-like and cry32Da-like showed a similarity of $88 \%$ to each other (at the amino acid level) and both carried the predicted conserved domains Endotoxin_N, Endotoxin_M, and Delta_Endotoxin_C, 
which are typical of the three-domain Cry proteins. The cry32Eb-like gene showed low similarity to the other two cry32-like genes (61\% amino acid similarity to cry32Ea-like and $64 \%$ amino acid similarity to cry32Da-like) and did not show any conserved domains. The cry73Aa-like gene also showed the predicted conserved domains Endotoxin_N, Endotoxin_M, and Delta_Endotoxin_C.

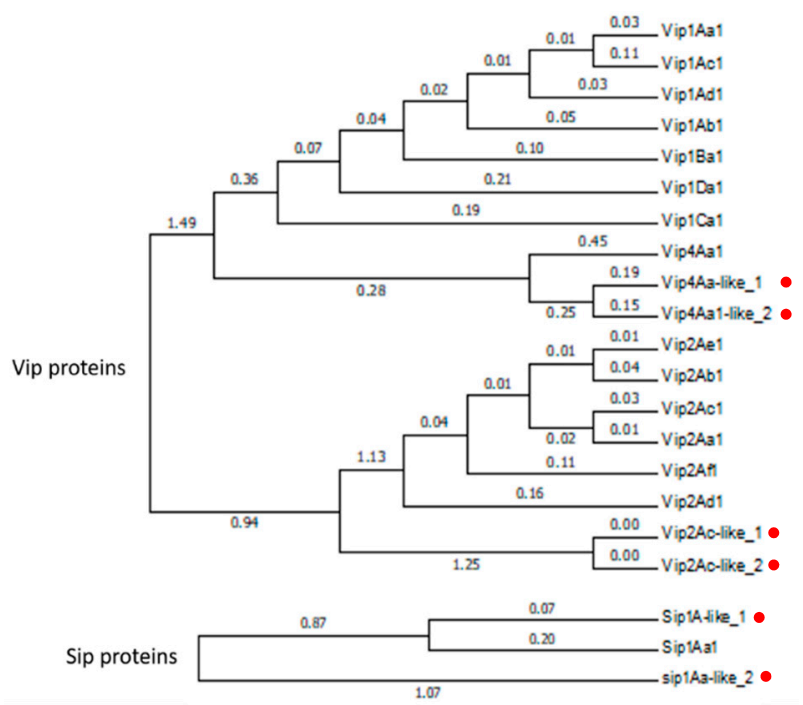

Figure 2. Phylogenetic analysis of the Vip1/Vip2- and Sip1A-type proteins detected in the Bt isolates E-SE10.2 and O-V84.2. The red dots indicate the position of the new putative proteins in the phylogenetic tree. Branch lengths represent the number of substitutions per site of the multiple-sequence alignment as a measure of divergence (Mega v6 software).

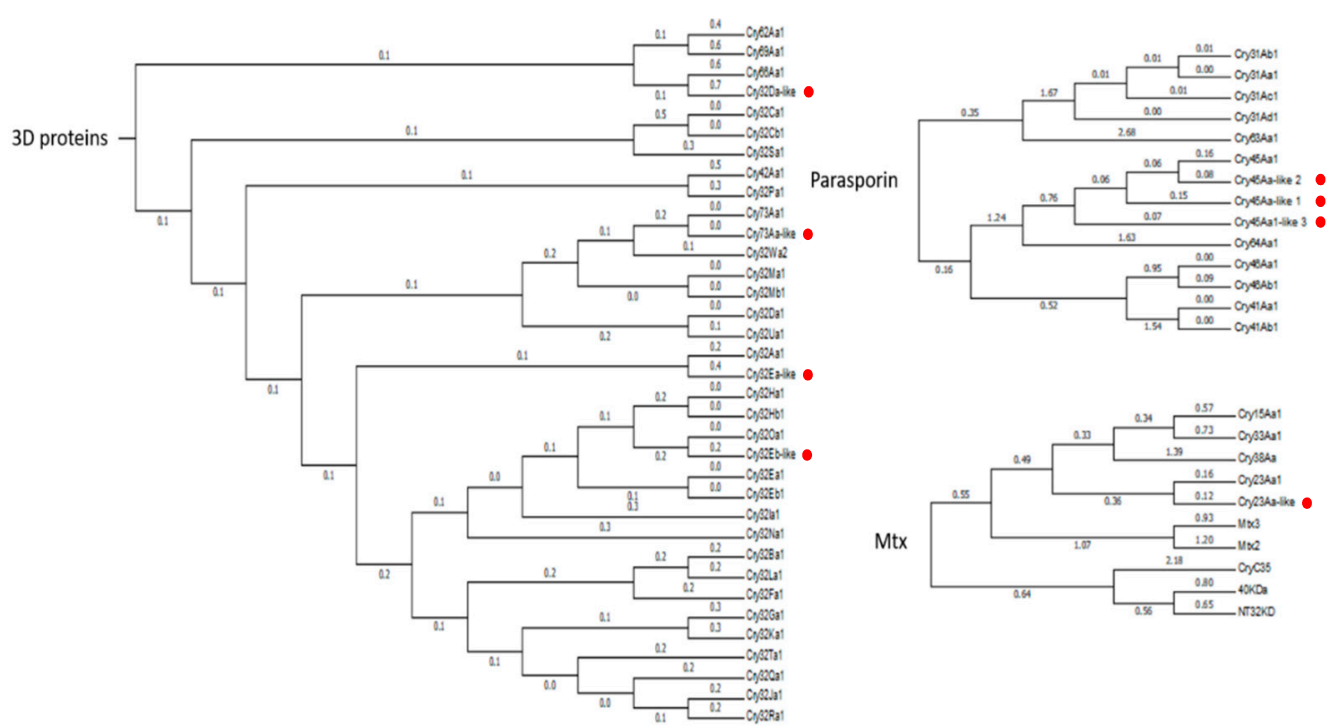

Figure 3. Phylogenetic analysis of the Cry-type proteins detected in the Bt isolates E-SE10.2 and O-V84.2. The red dots indicate the position of the new putative proteins in the phylogenetic tree. Branch lengths represent the number of substitutions per site of the multiple-sequence alignment as a measure of divergence (Mega v6 software).

2.6. Relative Abundance of the Putative Insecticidal Proteins in the Supernatant and in the Crystal of the Bt Isolates E-SE10.2 and O-V84.2

To determine the relative abundance of the putative insecticidal protein genes in the supernatants and crystals of the Bt isolates E-SE10.2 and O-V84.2, we performed two types of analyses: first, an emPAI analysis to determine the relative abundance within a same replicate at a given time (Table 5 
and Table S3); and, second, a label free analysis to compare between different times in the log phase (T1 vs. T2) (Table 6 and Table S4). The results showed that the putative vegetative insecticidal proteins were minimally expressed in the supernatant of both $B t$ isolates, being the most abundant protein flagellin FlaA (Table 5). In the Bt isolate E-SE10.2, among the putative insecticidal proteins found in the supernatant, the most abundant in all replicates was the Cry23Aa-like protein. In contrast, for O-V84.2, all secretable proteins were similarly represented (Table 5). Regarding the relative abundance of the proteins in the solubilized crystals, the crystal of E-SE10.2 contained only the Cry23Aa-like protein. In the case of O-V84.2, the percent weight corresponding to Cry proteins was close to the $50 \%$ of the solubilized proteins from the crystal (Table 5), being the most abundant, by far, the Cry32Ea-like protein.

To be able to compare the expression level of the proteins between $24 \mathrm{~h}$ and $48 \mathrm{~h}$, a label free analysis was performed (Table 6 and Table S4). Only the putative insecticidal proteins Vip4Aa-like_1 and Vip4Aa-like_2, from the Bt isolate O-V84.2, showed significant differences at the two growth phases (Tables 5 and 6). The former increased two-fold at $48 \mathrm{~h}$ compared to $24 \mathrm{~h}$ (Table 6), and the latter was only found at $24 \mathrm{~h}$ but not at $48 \mathrm{~h}$ (Table 5). The other proteins found in the supernatant did not show statistical differences in their production at $24 \mathrm{~h}$ vs. $48 \mathrm{~h}$.

Table 5. Estimation of the relative production expressed as weight percentage of the insecticidal protein genes in the supernatant and solubilized proteins from the spore and crystal mixtures of the $B t$ isolates E-SE10.2 and O-V84.2 identified with Mascot.

\begin{tabular}{|c|c|c|c|c|c|c|}
\hline \multirow{2}{*}{ Supernatant } & \multicolumn{3}{|c|}{24 h (\% Weight) } & \multicolumn{3}{|c|}{$48 \mathrm{~h}$ (\% Weight) } \\
\hline & R1 & $\mathbf{R} 2$ & R3 & R1 & R2 & R3 \\
\hline \multicolumn{7}{|l|}{ E-SE10.2 } \\
\hline Non Secretable toxins & 98.56 & 99.06 & 99.36 & 97.87 & 99.26 & 99.63 \\
\hline Flagellin protein FlaA & 55.21 & 73.82 & 87.19 & 39.75 & 36.04 & 43.19 \\
\hline Secretable toxins & 1.44 & 0.94 & 0.64 & 2.13 & 0.74 & 0.37 \\
\hline Vip2Ac-like_1 & 0.09 & 0.06 & 0.03 & 0.09 & 0.10 & 0.06 \\
\hline Sip1A-like_1 & 0.09 & 0.03 & 0.02 & 0.06 & 0.08 & 0.02 \\
\hline Cry23Aa-like * & 1.26 & 0.85 & 0.59 & 1.98 & 0.56 & 0.29 \\
\hline \multicolumn{7}{|l|}{ O-V84.2 } \\
\hline Non Secretable toxins & 99.99 & 99.99 & 99.99 & 99.99 & 99.99 & 99.99 \\
\hline Flagellin protein FlaA & 99.20 & 99.37 & 98.35 & 84.14 & 99.15 & 88.35 \\
\hline Secretable toxins & 0.0032 & 0.0012 & 0.0030 & 0.0111 & 0.00007 & 0.0075 \\
\hline Vip4Aa-like_1 & 0.0014 & 0.0008 & 0.0016 & 0.0019 & 0.00004 & 0.0029 \\
\hline Vip4Aa-like_2 & 0.0005 & 0.0001 & 0.0002 & - & - & - \\
\hline Vip2Ac-like_2 & 0.0013 & 0.0002 & 0.0010 & 0.0092 & 0.00003 & 0.0046 \\
\hline \multirow{2}{*}{ Crystal } & \multicolumn{6}{|c|}{$72 \mathrm{~h}$ (\% Weight) } \\
\hline & \multicolumn{2}{|c|}{ R1 } & \multicolumn{2}{|c|}{$\mathbf{R} 2$} & \multicolumn{2}{|c|}{ R3 } \\
\hline \multicolumn{7}{|l|}{ E-SE10.2 } \\
\hline Non-crystal toxins & \multicolumn{2}{|c|}{69.52} & \multicolumn{2}{|c|}{95.26} & \multicolumn{2}{|c|}{97.51} \\
\hline Crystal toxins & \multicolumn{2}{|c|}{30.48} & \multicolumn{2}{|c|}{4.74} & \multicolumn{2}{|c|}{2.49} \\
\hline Cry23A-like & \multicolumn{2}{|c|}{30.48} & \multicolumn{2}{|c|}{4.74} & \multicolumn{2}{|c|}{2.49} \\
\hline \multicolumn{7}{|l|}{ O-V84.2 } \\
\hline Non-crystal toxins & \multicolumn{2}{|c|}{52.86} & \multicolumn{2}{|c|}{51.12} & \multicolumn{2}{|c|}{53.25} \\
\hline Crystal toxins & \multicolumn{2}{|c|}{47.14} & \multicolumn{2}{|c|}{48.88} & \multicolumn{2}{|c|}{46.75} \\
\hline Cry45Aa-like_1 & \multicolumn{2}{|c|}{2.82} & \multicolumn{2}{|c|}{2.46} & \multicolumn{2}{|c|}{1.41} \\
\hline Cry45Aa-like_2 & & & & & & \\
\hline Cry45Aa-like_3 & & & & & & \\
\hline Cry32Ea-like & & & & & & \\
\hline Cry32Da-like & & & & & & \\
\hline Cry32Eb-like & & & & & & \\
\hline Cry73Aa-like & & & & & & \\
\hline
\end{tabular}

* The Cry23Aa-like protein was detected in the supernatant and the crystal of the Bt isolate E-SE10.2, but, according to the prediction of the SignalIP server 4.1, it is most likely not secretable. 
Table 6. Label free analysis of the putative insecticidal protein genes of the Bt isolates E-SE102 and O-V84.2 in the concentrated supernatant at $24 \mathrm{~h}$ versus $48 \mathrm{~h}$, identified with Protein Pilot v4.5.

\begin{tabular}{|c|c|c|c|c|c|c|c|c|c|}
\hline \multirow{2}{*}{$B t$ Isolate } & \multirow{2}{*}{ Proteins } & \multirow{2}{*}{$t$-Value ${ }^{\dagger}$} & \multirow{2}{*}{$p$-Value ${ }^{\phi}$} & \multicolumn{2}{|c|}{ Mean Peaks Area } & \multicolumn{2}{|c|}{ Standard Deviation Peaks Area } & \multirow{2}{*}{ Fold Change $24 / 48 \S$} & \multirow{2}{*}{ Status } \\
\hline & & & & $24 \mathrm{~h}$ & $48 \mathrm{~h}$ & $24 \mathrm{~h}$ & $48 \mathrm{~h}$ & & \\
\hline \multirow{3}{*}{ E-SE10.2 } & Vip2Ac-like_1 & 0.71 & 0.52 & 307,838 & 266,602 & 54,005 & 84,577 & 1.15 & No differences \\
\hline & Sip1Aa-like_1 & 0.89 & 0.42 & 110,172 & 76,938 & 47,032 & 44,040 & 1.43 & No differences \\
\hline & Cry23Aa-like * & 0.32 & 0.77 & $5,796,029$ & $4,858,544$ & $4,951,202$ & $1,257,383$ & 1.19 & No differences \\
\hline \multirow[t]{2}{*}{ O-V84.2 } & Vip4Aa-like_1 & 4.07 & 0.04 & 134,357 & 68,825 & 26,801 & 7636 & 1.95 & Increased \\
\hline & Vip2Ac-like_2 & 0.56 & 0.61 & 32,544 & 27,573 & 13,419 & 7512 & 1.18 & No differences \\
\hline
\end{tabular}

+ Student's $t$-test statistical analysis was performed between the concentrated supernatant at $24 \mathrm{~h}$ versus $48 \mathrm{~h}$. ${ }^{\phi}$ With a $\mathrm{p}$ value lower than 0.05 , it was considered that the differences observed between the concentrated supernatant at $24 \mathrm{~h}$ versus $48 \mathrm{~h}$ were statistically significant. $\$$ The fold change was calculated by dividing the mean value at $24 \mathrm{~h}$ by the mean values at $48 \mathrm{~h} .{ }^{*}$ The Cry23Aa-like protein was detected in the supernatant and the crystal of the Bt isolate E-SE10.2, but, according to the prediction of the SignalIP server 4.1, is most likely not secretable. 


\section{Discussion}

A screening of Spanish collections of $B t$ isolates was undertaken to search for novel members of the Vip family. As a result, nine $B t$ isolates were selected for harboring new binary insecticidal protein genes of the vip1/vip2 family [11]. As a first step, the PCR-Sanger Sequencing approach revealed new alleles of already described vip1 and vip2 genes (vip2Ac2-vip1Ca2 and vip2Bb4-vip1Bb3) and two sequences with low similarity to the vip1Bb1 (from the $B t$ isolate E-SE10.2) and vip4Aa1 (from the $B t$ isolate O-V84.2) genes. In a second step, the $B t$ isolates E-SE10.2 and O-V84.2 were subjected to whole genome sequencing with the Illumina HiSeq-PE150 sequencing platform. Then, the genomes of E-SE10.2 and O-V84.2 were assembled in 222 and 249 scaffolds codifying for 6156 CDS and 6457 CDS, respectively. The CDS predicted for both genomes represented close to the $99 \%$ of the total number of genes predicted in the genomes. In addition, from this $99 \%$ of the predicted CDS, $28 \%$ belonged to hypothetical genes and $72 \%$ to annotated genes by the Rast server. Moreover, the results obtained from the automated annotation indicated that both $B t$ genomes had a similar subsystems category distribution (Figure S1).

The supernatants at $24 \mathrm{~h}$ (growth Phase T1) and $48 \mathrm{~h}$ (growth Phase T2) and the crystal proteins (growth Phase T3) of both Bt isolates were also analyzed and annotated with GO terms (Figure S2). The quantity of the proteins expressed at the three different growth phases for the $B t$ isolates E-SE10.2 and O-V84.2 were $10.2-3.5 \%$ and $10.4-8.2 \%$, 8.3-2.8\%, respectively, of their genome encoded sequences. This low percentage of expressed proteins detected indicates that, in our experimental conditions, we only detect a small part of the predicted proteins by the genome data prediction, a phenomenon that has also been found in other studies [21,22]. The low percentage of detected expressed proteins should not be interpreted as that the rest of the proteins cannot be expressed, since they could do it under different growth conditions. Considering both isolates together, the number of annotated proteins in each growth phase, T1, T2 and T3, was $42.3 \%, 49.8 \%$ and $56.9 \%$, respectively. The distribution of the GO terms over the different growth phases is similar in the Bt isolates E-SE10.2 and O-V84.2 (Figure S2). The most common and abundant GO terms in all the phases (cellular biosynthetic process, organic substance biosynthetic process, cellular nitrogen compound metabolic process, and organonitrogen compound metabolic process) indicate that both $B t$ isolates metabolize the carbon and nitrogen in the media to produce all the organic and organonitrogen compounds that they need (Figure S2). The specific GO term macromolecule metabolic process of the T3 growth phase indicates that both $B t$ isolates express proteins of a relatively high molecular mass, such as the Cry-like proteins detected (Figure S2).

Regarding the predicted insecticidal protein genes in both $B t$ genomes, we were able to find some of the predicted gene products: one new couple of binary Vip-like proteins (Vip2Ac-like_1-Vip4Aa-like_1), two new Vip-like proteins (Vip2Ac-like_1 and Vip4Aa-like_2), one Sip1A-like protein (Sip1A-like_1), and eight Crystal-like proteins (Cry23A-like, Cry45Aa-like_1, Cry45Aa-like_2, Cry45Aa-like_3, Cry32Ea-like, Cry32eDa-like, Cry32Eb-like and Cry73Aa-like) (Table 4). The discrepancies of the protein identification between the replicates can be attributed to metabolic flow changes in cells during development, resulting from enzyme-related changes or that some proteins exist with extremely low abundances such that they cannot be detected by MS. To determine if the detected Bt-like proteins are being secreted or that they form inclusion bodies, we performed an LC/MSMS analysis with the supernatant ( $24 \mathrm{~h}$ and $48 \mathrm{~h}$ ) and solubilized crystal proteins. In the supernatant of both $B t$ isolates at $24 \mathrm{~h}$, the Vip4Aa-like_1, Vip4Aa-like_2, Vip2Ac-like_1, Vip2Ac-like_2, and Sip1Aa-like_1 proteins were detected, while at $48 \mathrm{~h}$ only Vip4Aa-like_1, Vip2Ac-like_1, Vip2Ac-like_2, and Sip1Aa-like_1 were detected. Again, the extremely low abundance of these proteins might be responsible for the differences found at $24 \mathrm{~h}$ and $48 \mathrm{~h}$. Regarding the Vip4Aa-like proteins, this is the first time that there has been demonstrated that they are expressed and secreted to the medium in the log phase. Regarding the crystal proteins, they were found in the crystal of both $B t$ isolates, except for the Cry23Aa-like, which was also found in the supernatant at $24 \mathrm{~h}$ and $48 \mathrm{~h}$. The detection of the Cry23Aa-like protein and sporulation factors (Stage 
V sporulation protein, spore coat protein $B$, spore coat polysaccharide biosynthesis protein spsB and spore coat polysaccharide synthesis) in the supernatant at $24 \mathrm{~h}$ (and also at $48 \mathrm{~h}$ ) of the Bt isolate E-SE10.2 indicates that the cells already started the sporulation process.

The relative abundance of the Bt-like proteins was estimated in the supernatant and the parasporal crystal in both $B t$ isolates. In the supernatant $(24 \mathrm{~h}$ and $48 \mathrm{~h})$ of both $B t$ isolates, the Vip-like, Sip1-like and Cry23Aa-like were marginally expressed. Regarding the crystal proteins in the $B t$ isolate O-V84.2, the Cry-like proteins represent around the half of the total crystal weight, while for the $B t$ isolate E-SE10.2, the Cry23Aa-like protein represents between $2.5 \%$ and $30 \%$ of the crystal weight. The high variability observed in the amount of Cry23Aa-like could be due to the different replicates are not in the same time point of the sporulation process. The crystal composition of the $B t$ isolate O-V84.2 was also determined for those proteins with a percentage of similarity lower than $45 \%$. The crystal was composed by four kinds of proteins: 7.0-9.8\% Cry45-like proteins (Cry45Aa-like_1, Cry45Aa-like_2 and Cry45Aa-like_3), 30.4-30.5\% Cry32-like proteins (Cry32Ea-like and Cry32Da-like), 5.0-6.2\% Cry32Eb-like, and 2.8-4.25\% Cry73Aa-like, while the Bt isolate E-SE10.2 only produced the Cry23Aa-like protein.

The expression levels of the Vip-like, Sip1-like and Cry23Aa-like proteins were compared between $24 \mathrm{~h}$ and $48 \mathrm{~h}$. The amount of Vip4Aa-like_1 protein was increased two-fold at $24 \mathrm{~h}$ vs. $48 \mathrm{~h}$, while the Vip4Aa-like_2 was only detected at $24 \mathrm{~h}$. As regard to the rest of the proteins (Vip2Ac-like, Sip1A-like, and Cry23A-like proteins), no differences in expression were observed. These results suggest that the Vip4Aa-like_2, Vip2A-like and Sip1A-like proteins were expressed at the $24 \mathrm{~h}$ while the Vip4Aa-like_1 was expressed later at the end of the $24 \mathrm{~h}$ and the beginning of the $48 \mathrm{~h}$ periods.

\section{Conclusions}

In summary, the combined use of the genomic and proteomic data allowed us to determine which of the identified insecticidal protein genes, present in the $B t$ isolates E-SE10.2 and O-V84.2, are being expressed and, if so, at which relative abundance. Considering the two $B t$ isolates together, we were able to identify five new insecticidal protein genes that are expressed within the first $24 \mathrm{~h}$, except for vip4Aa-like_1, which is expressed after the $24 \mathrm{~h}$. In the parasporal crystals, we found nine new crystal proteins. The spore/crystal mixture of the Bt isolate E-SE10.2 contains solely the Cry23Aa-like protein, while the crystal of the Bt isolate O-V84.2 contains four kinds of Cry proteins: Cry45-like, Cry32-like, Cry32Eb-like, and Cry73Aa-like.

\section{Materials and Methods}

\subsection{Bacterial Strains and Growth Conditions for DNA Analysis}

Nine $B t$ isolates from a Spanish collection, known to carry vip1 and vip2 genes, were selected for this study [11]. For further gene identification of the vip1 and vip2 genes, the $B t$ isolates were grown in $4 \mathrm{~mL} \mathrm{LB}$ medium overnight (ON) at $29^{\circ} \mathrm{C}$ and $200 \mathrm{rpm}$. For the whole genome sequencing, only those $B t$ isolates with vip 1 and vip 2 genes with less than $60 \%$ similarity to already described vip 1 and vip2 genes were chosen. The isolates were grown in $10 \mathrm{~mL}$ LB medium until OD of 0.6 at $29^{\circ} \mathrm{C}$ and $200 \mathrm{rpm}$.

\subsection{Genomic DNA Preparation}

Total genomic DNA used for gene identification (GI) was isolated from a single colony of the $B t$ isolates. Cells were collected at $9000 \times g$ for $10 \mathrm{~min}$ at $4{ }^{\circ} \mathrm{C}$ and the pellet was washed in $2 \mathrm{~mL}$ of TE buffer (1 M Tris-HCl, $10 \mathrm{mM}$ EDTA, pH 8.0). The pellet was dissolved in $200 \mu \mathrm{L}$ of TEL buffer (TE buffer $+4 \mathrm{mg} / \mathrm{mL}$ lysozyme) and further incubated at $37^{\circ} \mathrm{C}$ for $30 \mathrm{~min}$. Then, $400 \mu \mathrm{L}$ of lysis solution $(0.2 \mathrm{M} \mathrm{NaOH}, 1 \% \mathrm{SDS})$ was added. After gentle mixing, $300 \mu \mathrm{L}$ of the neutralization buffer ( $3 \mathrm{M} \mathrm{KAc}, \mathrm{pH}$ 5.5) was added and the mixture incubated for $5 \mathrm{~min}$ on ice. The mixture was centrifuged at $14,000 \times g$ for $15 \mathrm{~min}$ at $4{ }^{\circ} \mathrm{C}$ and the supernatant was transferred to a new tube. One volume of cold 
$100 \%$ ethanol was added and the samples kept at $-20^{\circ} \mathrm{C}$ for $16 \mathrm{~h}$. The samples were centrifuged at $14,000 \times g$ for $15 \mathrm{~min}$ at $4{ }^{\circ} \mathrm{C}$ and the supernatant was transferred to a new tube and the pellet washed with $1 \mathrm{~mL}$ of cold 70\% ethanol. The pellet was dried with the Eppendorf concentrator 5301 for 5 min at $42{ }^{\circ} \mathrm{C}$ and solubilized in $50 \mu \mathrm{L}$ of TE buffer. Total genomic DNA, used for whole genome sequencing (WGS), was purified as described in the manufacturer instructions of the DNeasy Blood \& Tissue Kit Qiagen. The DNA for GI was quantified using Nanodrop 2000 (Thermo Scientific, Waltham, MA, USA), while for WGS, the DNA was measured with a Qubit Fluorimetrer. In addition, the integrity of the DNA for GI and WGS was evaluated by agarose gel electrophoresis (1\% agarose).

\subsection{Identification of Vip1- and Vip2-Type Genes}

Identification of vip1 and vip2 genes was performed with primer pairs designed from conserved regions within the vip1 and vip2 gene families, respectively. A first PCR with "screening primers" [11] was performed to confirm the presence of vip genes. With the positive samples, a second PCR was performed with the "typing primers" [11,23] for the identification of the vip1 and vip2 genes. PCR reactions contained, in a final volume of $25 \mu \mathrm{L}, 100 \mathrm{ng}$ of the DNA template, $0.25 \mathrm{U}$ of Biotools polymerase (Biotools), $2.5 \mu \mathrm{L}$ of 10 -fold reaction buffer, $10 \mathrm{mM}$ of each $\mathrm{dNTPs}$, and $0.3 \mu \mathrm{M}$ of the corresponding primers (vip1sc, vip2sc, vip2 typing [11] or vip1 typing [23]). PCR amplifications were carried out in an Eppendorf Mastercycler thermal cycler as follows: 5 min denaturation at $95{ }^{\circ} \mathrm{C}$, 35 cycles of amplification $\left(1 \mathrm{~min}\right.$ denaturation at $94{ }^{\circ} \mathrm{C}, 1 \mathrm{~min}$ of annealing at $45^{\circ} \mathrm{C}$, and $2 \mathrm{~min}$ of extension at $72{ }^{\circ} \mathrm{C}$ ), and an extra extension step of $10 \mathrm{~min}$ at $72{ }^{\circ} \mathrm{C}$. To determine the similarity of the amplified sequences to already described vip1 and vip2 genes, the PCR products obtained with the "typing primers" (or with the "screening primers" for those samples that did not give amplification with the "typing primers") were ligated into the pGEM $^{\circledR}$-T Easy plasmid (Promega), cloned in Escherichia coli DH10 $\beta$, and sequenced. DNA sequence analysis and contig assembly was performed using DNAstar v5 and NCBI BLAST tools (Blastx) [24].

\subsection{Genome Sequencing, Assembly and Annotation Analysis}

Genome Sequencing for the Bt isolates E-SE10.2 and O-V84.2 was performed with the Illumina HiSeq-PE150 sequencing platform (Novogene S.L Hong Kong, China). From the clean reads (without adapters, low quality, $\mathrm{N}$ and duplication) provided by Novogene S.L., first we evaluated the quality of the data with FastQC software (0.11.5, Babraham Bioinformatics Institute, Cambridge, Cambridgeshire, United Kingdom, 2016). Then, the reads were assembled with SoapdeNovo2 (kmer size 35 and genome size 5,600,000 bp) and the gaps were closed with GapCloser (maximum read length 150, overlap $25 \mathrm{bp}$ and thread number 1) [25]. The assembled reads were annotated with Rast server (Figure S1) and the coding sequence (CDS) prediction was performed with the Glimmer v2 [26]. First, the predicted genes were filtered against a customized Bt protein database (https:/ / sourceforge.net/projects/btproteindatabase/files/Btdatabase/) with Blastx (genetic code bacteria and archaea, e-value 0.001 and word size 6) to select those CDS with homology to the Bt toxins [24]. Next, the putative insecticidal protein genes were compared against the Non-Redundant database and only the concordant results along the customized Bt protein database and Non-Redundant database were selected as true positive. Moreover, for the selected putative insecticidal genes, prediction of conserved domains was carried out with CD-search [27] and the gene sinteny was determined in the assembled sequences.

\subsection{Sample Preparation for in Gel Digestion LC/MSMS Analysis and Insecticidal Activity of Bt Isolates}

A single colony of $B t$ was grown in $100 \mathrm{~mL}$ of LB at $29^{\circ} \mathrm{C}$ for $24 \mathrm{~h}$ and $48 \mathrm{~h}$ for detection of the secretable proteins, while for the detection of proteins in the parasporal crystal the culture was grown in $100 \mathrm{~mL}$ of $\mathrm{CCY}$ at $29^{\circ} \mathrm{C}$ until culture sporulation $(72 \mathrm{~h})$. The supernatant of $\mathrm{Bt}$ was concentrated by trichloroacetic acid (TCA) precipitation. Briefly, the cells were collected at $6000 \times g$ for 15 min at $4{ }^{\circ} \mathrm{C}$ and filtered through sterile $0.45 \mu \mathrm{m}$ cellulose acetate filters (GE Healthcare Life Sciences). The sample was incubated with $10 \%$ TCA (final concentration) and kept at $4{ }^{\circ} \mathrm{C}$ for $24 \mathrm{~h}$. Then, the 
sample was centrifuged at $16,000 \times g$ for $20 \mathrm{~min}$ at $4{ }^{\circ} \mathrm{C}$. The pellet was washed with $100 \mathrm{~mL}$ of cold acetone $\left(-18^{\circ} \mathrm{C}\right)$, centrifuged at $16,000 \times \mathrm{g}$ for $20 \mathrm{~min}$ at $4{ }^{\circ} \mathrm{C}$, and let dry at room temperature for $5 \mathrm{~min}$. The precipitated proteins were solubilized in $50 \mathrm{mM}$ carbonate buffer containing $10 \mathrm{mM}$ dithiothreitol ( $\mathrm{pH}$ 11.3) for $48 \mathrm{~h}$, with two buffer changes (Figure S3). Crystals (together with spores) were separated by centrifugation at $6000 \times g$ for $12 \mathrm{~min}$ at $4{ }^{\circ} \mathrm{C}$. The pellet containing the parasporal crystals was washed three times with ice cold solution A ( $1 \mathrm{M} \mathrm{NaCl}, 5 \mathrm{mM}$ EDTA, $10 \mathrm{mM} \mathrm{PMSF}, 1 \%$ Triton X-100) and centrifuged at $17,000 \times \mathrm{g}$ for $12 \mathrm{~min}$ at $4{ }^{\circ} \mathrm{C}$ between washes. The pellet was then washed three times with ice cold solution $\mathrm{B}(10 \mathrm{mM} \mathrm{KCl})$ and centrifuged at $24,000 \times \mathrm{g}$ for $15 \mathrm{~min}$ at $4{ }^{\circ} \mathrm{C}$. The crystals in the final pellet were solubilized in $20 \mathrm{~mL}$ of $50 \mathrm{mM}$ carbonate buffer containing $10 \mathrm{mM}$ dithiothreitol ( $\mathrm{pH}$ 11.3) by incubation at room temperature for $2 \mathrm{~h}$ with continuous shaking (Figure S3). Concentration of the proteins in the supernatant and in the solubilized crystals was estimated with the Bradford method [28]. The purity of the expressed proteins in the supernatant and the crystal was analyzed by SDS-PAGE and stained with Coomassie brilliant blue R-250 (Sigma-Aldrich, St. Louis, MO, USA) (Figure S3).

\subsection{In Gel Digestion LC/MSMS Analysis}

The detection of the expression of the putative insecticidal proteins was done by LC/MSMS at the proteomics facility of the SCSIE (Servei Central de Suport a la Investigació Experimental), at the University of Valencia, Spain. First, a 1D SDS-PAGE (without resolving gel) was performed with $30 \mu \mathrm{g}$ of total protein in three replicates of the concentrated supernatant ( $24 \mathrm{~h}$ and $48 \mathrm{~h}$ ) and solubilized crystal proteins. The bands were cut out and in gel digested with $500 \mathrm{ng}$ sequencing grade trypsin (Promega). The digestion was stopped with trifluoroacetic acid (TFA, 1\% final concentration). After subjecting the samples to a double extraction with acetonitrile (ACN), all the peptide solutions were dried in a rotatory evaporator. Samples were solubilized with $50 \mu \mathrm{L}$ of $2 \% \mathrm{ACN}, 0.1 \%$ TFA. A sample aliquot of $5 \mu \mathrm{L}$ was loaded onto a trap column (NanoLC Column, $3 \mu \mathrm{C} 18-\mathrm{CL}, 350 \mu \mathrm{m} \times 0.5 \mathrm{~mm}$, Eksigent) and desalted with $0.1 \%$ TFA at $3 \mu \mathrm{L} / \mathrm{min}$ for $5 \mathrm{~min}$. The peptides were then loaded onto an analytical column (LC Column, $3 \mu \mathrm{C} 18-\mathrm{CL}, 75 \mu \mathrm{m} \times 12 \mathrm{~cm}$, Nikkyo) equilibrated in $5 \%$ ACN $0.1 \%$ formic acid (FA). The elution was carried out with a linear gradient of $5-35 \% \mathrm{~B}$ in A for $30 \mathrm{~min}$ (A: $0.1 \%$ FA; B: ACN, $0.1 \%$ FA) at a flow rate of $0.3 \mu \mathrm{L} / \mathrm{min}$. Peptides were analyzed in a nanoESI qQTOF (5600 TripleTOF, ABSCIEX) mass spectrometer. Eluted peptides were ionized applying $2.8 \mathrm{kV}$ to the spray emitter. Analysis was carried out in a data-dependent mode (DDA). Survey MS1 scans were acquired from 350 to $1250 \mathrm{~m} / z$ for $250 \mathrm{~ms}$. The quadrupole resolution was set to "UNIT" for MS2 experiments, which were acquired 100-1500 m/z for $50 \mathrm{~ms}$ in "high sensitivity" mode. The following switch criteria were used: charge: $2+$ to $5+$; minimum intensity; 70 counts per second (cps). Up to 25 ions were selected for fragmentation after each survey scan and the collision energy was automatically selected by the instrument according to the following equation: $|\mathrm{CE}|=($ slope $) \times(\mathrm{m} / z)+$ (intercept); Charge (Unknown, 1, 2, 3, 4, 5), Slope $(0.0575,0.0575,0.0625,0.0625,0.0625,0.0625)$, Intercept $(9,9,-3$, $-3,-6,-6)$

\subsection{Protein Identification of the in Gel Digestion LC/MSMS Analysis with Paragon Algorithm and Mascot}

The MS/MS information of three replicates of the concentrated supernatant ( $24 \mathrm{~h}$ and $48 \mathrm{~h}$ ) and solubilized crystal proteins were sent to Paragon algorithm [29] via the Protein Pilot v 4.5 (ABSciex). Protein Pilot v 4.5 default parameters were used to generate peak list directly from the 5600 TripleTof Sciex. The Paragon algorithm of Protein Pilot v 4.5 was used to search in a homemade database that was created combining all the coding sequences predicted by Glimmer v2 software for the $B t$ isolates E-SE10.2 and O-V84.2; the new database was named Bt_combined (https:/ / sourceforge.net/projects/ bt-combined/files/Bt_combined/). The search in the respective protein database was done with the following parameters: trypsin specificity, cys-alkylation, and the search effort set to through. To avoid using the same spectral evidence in more than one protein, the identified proteins were grouped based on MS/MS spectra (proteins sharing MS/MS spectra are grouped, regardless of the peptide 
sequence assigned) by the Protein-Pilot Progroup algorithm. A protein group in a Progroup Report is a set of proteins that share some physical evidence, the formation of protein groups in Pro Group was guided entirely by observed peptides only and the unobserved regions of protein sequence play no role in explaining the data (Tables S1 and S2). The protein within each group which can explain more spectral data is that protein shown as the primary protein of the group. Only the proteins of the group for which there is individual evidence (unique peptides with enough confidence) are also listed (Tables S1 and S2). In addition, to support the identification of the Protein Pilot v 4.5 (ABSciex) and estimate the relative production of the insecticidal proteins in the three replicates of the concentrated supernatant and solubilized crystal proteins, a series of Mascot MS/MS ion searches with the output of the 5600 TripleTof Sciex were done with the Bt_combined protein database. The following parameters were used: MS/MS "ion search", enzyme "trypsin", fixed modifications "carbamidomethyl (C)", variable modifications "deamidated (NQ) and oxidation (M)", mass values "monoisotopic", protein mass "unrestricted", peptide mass tolerance "50 ppm", fragment mass tolerance "0.6 Da", max miss cleavages "1", instrument type "ESI-QUAD-TOF", number of queries for E-SE10.2 "(Supernatant 24 h: R1 7468, R2 8755, R3 7682; Supernatant 48 h: R1 9, 243, R2 8602, R38,286; Crystal: R1 6779, R2 7173 R3 7790)" and for O-V84.2 “(Supernatant 24 h: R1 3708, R2 4459, R3 3536 Supernatant 48 h: R1 6016, R2 6654, R3 6123; Crystal: R1 5206 R2 5206 R3 4476)", significance threshold " $p$-value < 0,05", max number of families "auto", ions score or expect cut-off "20", and preferred taxonomy "all entries". The Exponentially Modified Protein Abundance Index (emPAI) was expressed as molar and weight percentage [30] (Table 5 and Table S3).

We defined as a true positive all those proteins with homology to the $B t$ toxins higher than 100 aa that had been identified with Protein Pilot v4.5 and Mascot in at least two of the replicates. In addition, for the identified proteins, the functional annotation was performed with the SwissProt Database using the Blast2GO v5.0 software (Figure S2) [31].

\subsection{Label Free Analysis of the Concentrated Supernatant $24 \mathrm{~h}$ vs. $48 \mathrm{~h}$ in Both Bt Isolates}

The data obtained from the 5600 TripleTof Sciex of the concentrated supernatant and solubilized proteins from the crystal were analyzed by Peak View 1.1 following the parameters: Unused $\geq 1.3$, confidence $>95 \%$ and with maximum 50 peptides for protein. For the protein library construction of the global analysis, a joint search with the Bt_combined protein database was performed with the three replicates of the concentrated supernatant ( $24 \mathrm{~h}$ and $48 \mathrm{~h}$ ) and solubilized crystal proteins (Table S5). In the case of the specific conditions analysis (Supernatant: E-SE10.2 $24 \mathrm{~h}$ vs. $48 \mathrm{~h}$, and O-V84.2 $24 \mathrm{~h}$ vs. $48 \mathrm{~h}$ ), a joint search with the $B t_{-}$combined protein database was performed with the three replicates of the concentrated supernatant (Table S4). The search in the respective analysis was done with the following parameters: trypsin specificity, cys-alkylation, and the search effort set to through. First, a global analysis was done to study grouped data analysis and samples distribution. A joined search with all the samples was performed with the Peak View 1.1 that identified 1816 proteins and the quantitative data obtained was analyzed with Marker View 1.3. Briefly, for the grouped data analysis, a PCA analysis was done with the non-normalized area of the peaks and with the area peaks corrected by the total areas sum. In the case of the samples distribution, a PCA analysis was done with the area of the peaks corrected by the total areas sum (Table S5). For the specific conditions analysis, a specific search with Peak View 1.1 was done with the respective samples to study the statistical significant differences. The quantitative data was analyzed with Marker View 1.3. Prior to data analysis of the E-SE10.2 $24 \mathrm{~h}$ vs. $48 \mathrm{~h}$, and O-V84.2 $24 \mathrm{~h}$ vs. $48 \mathrm{~h}$, we applied a normalization by total areas sum, and then a grouped data analysis with PCA analysis was done. A student's $t$-test statistical analysis with the concentrated supernatant (E-SE10.2 $24 \mathrm{~h}$ vs. $48 \mathrm{~h}$, and O-V84.2 $24 \mathrm{~h}$ vs. $48 \mathrm{~h}$ ) was performed to determine the differentially expressed proteins between two experimental conditions with the Marker View 3.1 software (Table S4). 
Supplementary Materials: The following are available online at http:/ / www.mdpi.com/2072-6651/10/5/193/s1, Figure S1: Subsystem category distribution of the Bt isolates E-SE10.2 and O-V84.2 by the genome annotation based on the Rast server. The right pie chart indicates the percentage or predicted encoding genes associated to at least one subsystem; Figure S2: Functional annotation of the protein identification from the concentrated supernatants at $24 \mathrm{~h}$ and $48 \mathrm{~h}$ in LB medium, and of the solubilized proteins from the crystal at $72 \mathrm{~h}$ in CCY medium. The number of sequences that belong to the group are indicated in brackets; Figure S3: SDS-PAGE of the three replicates of the concentrated supernatants and solubilized proteins from the spore/crystal mixtures and growth curve of the Bt isolates E-SE10.2 and O-V84.2; Table S1: Protein summary of three replicates of concentrated supernatants and solubilized proteins from spore/crystal mixtures with Protein Pilot v4.5; Table S2: Peptide summary of three replicates of concentrated supernatants and solubilized proteins from spore/crystal mixtures identified with Protein Pilot v4.5; Table S3: Result of the Mascot search in the three replicates of the concentrated supernatants and solubilized proteins form spore/crystal mixtures; Table S4: Label free analysis at $24 \mathrm{~h}$ vs. $48 \mathrm{~h}$ of concentrated supernatants of the proteins identified with Protein Pilot v4; Table S5: Protein library construction and PCA analysis of the joint search with the concentrated supernatants and solubilized proteins from spore/crystal mixtures identified with Protein Pilot v4.5.

Availability of Data and Material: The clean reads of the $B t$ isolates have been deposited at Sequence Read Archive (SRA). E-SE10.2 SRR5115619 and O-V84.2 SRR5121303. The sequences of the genes have been deposited in the GenBank. V-J20.2: vip1Bb3 (KR065727) and vip2Bb4 (KR065728). V-V54.26: vip1Ca2 (KR065725) and vip2Ac2 (KR065726). E-SE10.2: vip2Ac-like_1 (KY420183), sip1Aa-like_1 (KY420184), cry23Aa-like (KY420185). O-V84.2: vip4Aa-like_1 (KY420182), vip4Aa-like_2 (KY420193), vip2Ac-like_2 (KY420195), vip2Ac-like_3 (KY420197), cry45Aa-like_1 (KY420188), cry45Aa-like_2 (KY420189), cry32Ea-like (KY420190), cry32Da-like (KY420191), cry45Aa1-like_3 (KY420192), cry73Aa-like (KY420194), cry32Eb-like (KY420196).

Author Contributions: J.G.-C., A.P.S.R., and J.F. conceived and designed the experiments. J.G.-C. and A.P.S.R. performed the experiments. J.G.-C., A.P.S.R. and J.F. analyzed the data. J.G.-C. and J.F. wrote the paper.

Funding: This research was supported by the Spanish Ministry of Economy and Competitivity (grants AGL2009-13340-C02-01 and AGL2012-39946-C02-01), by grants from the Generalitat Valenciana (ACOMP/2011/094, PROMETEO 2011/044 and GVPROMETEOII-2015-001), and by European FEDER funds. JGC was recipient of a PhD grant from the Spanish Ministry of Economy and Competitivity (grant BES-2013-065848). APSR was supported CAPES (Coordination for the Improvement of Higher Education Personnel) scholarship from Brazil.

Acknowledgments: We thank R. González-Martínez and O. Marín-Vázquez for their help in rearing the insect colonies The proteomic analysis was performed in the proteomics facility of SCSIE University of Valencia that belongs to ProteoRed, PRB2-ISCIII, supported by grant PT13/0001 of the PE I+D+i 2013-2016, funded by ISCIII and FEDERPT13/0001.

Conflicts of Interest: The authors declare no conflict of interest.

\section{References}

1. Palma, L.; Muñoz, D.; Berry, C.; Murillo, J.; Caballero, P. Bacillus thuringiensis toxins: An overview of their biocidal activity. Toxins 2014, 6, 3296-3325. [CrossRef] [PubMed]

2. Chakroun, M.; Banyuls, N.; Bel, Y.; Escriche, B.; Ferré, J. Bacterial Vegetative Insecticidal Proteins (Vip) from Entomopathogenic Bacteria. Microbiol. Mol. Biol Rev. 2016, 80, 329-350. [CrossRef] [PubMed]

3. Ferré, J.; Van Rie, J. Biochemistry and genetics of insect resistance to Bacillus thuringiensis. Ann. Rev. Entomol. 2002, 47, 501-533. [CrossRef] [PubMed]

4. Ferré, J.; Van Rie, J.; MacIntosh, S.C. Insecticidal genetically modified crops and insect resistance management (IRM). In Integration of Insect-Resistanct Genetically Modified Crops within IPM Programs; Romeis, J., Shelton, A.M., Kennedy, G.G., Eds.; Springer: Dordrecht, The Netherlands, 2008.

5. Tabashnik, B.E.; Van Rensburg, J.B.J.; Carrière, Y. Field-evolved insect resistance to Bt crops: Definition, theory and data. J. Econ. Entomol. 2009, 102, 2011-2025. [CrossRef] [PubMed]

6. Tabashnik, B.E. ABCs of Insect Resistance to Bt. PLoS Genet. 2015, 11, e1005646. [CrossRef] [PubMed]

7. Kalman, S.; Kiehne, K.L.; Libs, J.L.; Yamamoto, T. Cloning of a novel cryIC-type gene from a strain of Bacillus thuringiensis subsp. galleriae. Appl. Environ. Microbiol. 1993, 59, 1131-1137. [PubMed]

8. Kuo, W.S.; Chak, K.F. Identification of novel cry-type genes from Bacillus thuringiensis strains on the basis of restriction fragment length polymorphism of the PCR-amplified DNA. Appl. Environ. Microbiol. 1996, 62, 1369-1377. [PubMed]

9. Juarez-Perez, V.M.; Ferrandis, M.D.; Frutos, R. PCR-based approach for detection of novel Bacillus thuringiensis cry genes. Appl. Environ. Microbiol. 1997, 63, 2997-3002. [PubMed] 
10. Lin, Y.; Fang, G.; Peng, K. Characterization of the highly variable cry gene regions of Bacillus thuringiensis strain ly4a3 by PCR-SSCP profiling and sequencing. Biotechnol. Lett. 2007, 29, 247-251. [CrossRef] [PubMed]

11. Hernández-Rodríguez, C.S.; Boets, A.; Van Rie, J.; Ferré, J. Screening and identification of vip genes in Bacillus thuringiensis. J. Appl. Microbiol. 2009, 107, 219-225. [CrossRef] [PubMed]

12. Schnepf, H.E.; Whiteley, H.R. Cloning and expression of the Bacillus thuringiensis crystal protein gene in Escherichia coli. Proc. Natl. Acad. Sci. USA 1981, 78, 2893-2897. [CrossRef] [PubMed]

13. Balasubramanian, P.; Jayakumar, R.; Shambharkar, P.; Unnamalai, N.; Pandian, S.K.; Kumaraswami, N.S.; Ilangovan, R.; Sekar, V. Cloning and characterization of the crystal protein-encoding gene of Bacillus thuringiensis subsp. yunnanensis. Appl. Environ. Microbiol. 2002, 68, 408-411. [CrossRef] [PubMed]

14. Kongsuwan, K.; Gough, J.; Kemp, D.; McDevitt, A.; Akhurst, R. Characterization of a new Bacillus thuringiensis endotoxin, Cry47Aa, from strains that are toxic to the Australian sheep blowfly, Lucilia cuprina. FEMS Microbiol. Lett. 2005, 252, 127-136. [CrossRef] [PubMed]

15. Fang, J.; Xu, X.; Wang, P.; Zhao, J.Z.; Shelton, A.M.; Cheng, J.; Feng, M.G.; Shen, Z. Characterization of chimeric Bacillus thuringiensis Vip3 toxins. Appl. Environ. Microbiol. 2003, 73, 956-961. [CrossRef] [PubMed]

16. Metzker, M.L. Sequencing technologies-The next generation. Nat. Rev. Genet. 2010, 11, 31-46. [CrossRef] [PubMed]

17. Shendure, J.; Ji, H. Next-generation DNA sequencing. Nat. Biotechnol. 2008, 26, 1135-1145. [CrossRef] [PubMed]

18. Huang, S.Y.; Ding, X.Z.; Sun, Y.J.; Yang, Q.; Xiao, X.Q.; Cao, Z.P.; Xia, L. Proteomic analysis of Bacillus thuringiensis at different growth phases by using an automated online two-dimensional liquid chromatography tandem mass spectrometry strategy. Appl. Environ. Microb. 2012, 78, 5270-5279. [CrossRef] [PubMed]

19. Gupta, N.; Benhamida, J.; Bhargava, V.; Goodman, D.; Kain, E.; Kerman, I.; Nguyen, N.; Ollikainen, N.; Rodriguez, J.; Wang, J.; et al. Comparative proteogenomics: Combining massspectrometry and comparative genomics to analyse multiple genomes. Genome Res. 2008, 18, 1133-1142. [CrossRef] [PubMed]

20. Yang, M.K.; Yang, Y.H.; Chen, Z.; Zhang, J.; Lin, Y.; Wang, Y.; Xiong, Q.; Li, T.; Ge, F.; Bryant, D.A.; et al. Proteogenomic analysis and global discovery of posttranslational Modifications in prokaryotes. Proc. Natl. Acad. Sci. USA 2014, 111, E5633-E5642. [CrossRef] [PubMed]

21. Quan, M.; Xie, J.; Liu, X.; Li, Y.; Rang, J.; Zhang, T.; Zhou, F.; Xia, L.; Hu, S.; Sun, Y.; et al. Comparative analysis of genomics and proteomics in the new isolates $\mathrm{X} 022$ reveals the metabolic regulation mechanism of Carbon flux following $\mathrm{Cu}^{2+}$ Treatment. Front. Microbiol. 2016, 7, 792. [CrossRef] [PubMed]

22. Rang, J.; He, H.; Wang, T.; Ding, X.; Zuo, M.; Quan, M.; Sun, Y.; Yu, Z.; Hu, S.; Xia, L. Comparative analysis of genomics and proteomic in Bacillus thuringiensis 4.0718. PLoS ONE 2015, 10, e0119065. [CrossRef] [PubMed]

23. Yu, X.; Liu, T.; Liang, X.; Tang, C.; Zhu, J.; Wang, S.; Li, S.; Deng, Q.; Wang, L.; Zheng, A.; et al. Rapid detection of vip1-type genes from Bacillus cereus and characterization of a novel vip binary toxin gene. FEMS Microbiol. Lett. 2011, 325, 30. [CrossRef] [PubMed]

24. Altschul, S.F.; Gish, W.; Miller, W.; Myers, E.W.; Lipman, D.J. Basic local alignment search tool. J. Mol. Biol. 1990, 215, 403-410. [CrossRef]

25. Luo, R.; Liu, B.; Xie, Y.; Li, Z.; Huang, W.; Yuan, J.; He, G.; Chen, Y.; Pan, Q.; Liu, Y.; et al. SOAPdenovo2: An empirically improved memory-efficient short-read de novo assembler. GigaScience 2012, 1, 18. [CrossRef] [PubMed]

26. Aziz, R.K.; Bartels, D.; Best, A.A.; DeJongh, M.; Disz, T.; Edwards, R.A.; Formsma, K.; Gerdes, S.; Glass, E.M.; Kubal, M.; et al. The RAST Server: Rapid annotations using subsystems technology. BMC Genom. 2008, 9, 75. [CrossRef] [PubMed]

27. Marchler-Bauer, A.; Derbyshire, M.K.; Gonzales, N.R.; Lu, S.; Chitsaz, F.; Geer, L.Y.; Geer, R.C.; He, J.; Gwadz, M.; Hurwitz, D.I.; et al. CDD: NCBI's conserved domain database. Nucleic Acids Res. 2015, 43, 222-226. [CrossRef] [PubMed]

28. Bradford, M.M. A rapid and sensitive method for the quantitation of microgram quantities of protein utilizing the principle of protein-dye binding. Anal. Biochem. 1976, 72, 248-254. [CrossRef]

29. Shilov, I.V.; Seymour, S.L.; Patel, A.A.; Loboda, A.; Tang, W.H.; Keating, S.P.; Hunter, C.L.; Nuwaysir, L.M.; Schaeffer, D.A. The Paragon Algorithm, a next generation search engine that uses sequence temperature values and feature probabilities to identify peptides from tandem mass spectra. Mol. Cell. Proteom. 2007, 6, 1638-1655. [CrossRef] [PubMed] 
30. Ishihama, Y.; Oda, Y.; Tabata, T.; Sato, T.; Nagasu, T.; Rappsilber, J.; Mann, M. Exponentially Modified Protein Abundance Index (emPAI) for Estimation of Absolute Protein Amount in Proteomics by the Number of Sequenced Peptides per Protein. Mol. Cell. Proteom. 2005, 4, 1265-1272. [CrossRef] [PubMed]

31. Conesa, A.; Götz, S.; García-Gómez, J.M.; Terol, J.; Talón, M.; Robles, M. Blast2GO: A universal tool for annotation, visualization and analysis in functional genomics research. Bioinformatics 2005, 21, 3674-3676. [CrossRef] [PubMed]

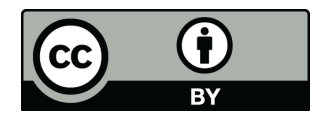

(C) 2018 by the authors. Licensee MDPI, Basel, Switzerland. This article is an open access article distributed under the terms and conditions of the Creative Commons Attribution (CC BY) license (http://creativecommons.org/licenses/by/4.0/). 